\title{
Hubungan Kurikulum Pendidikan Tahap Sarjana terhadap Kompetensi Mahasiswa pada Tahap Profesi di Rumah Sakit Pendidikan
}

\author{
Nurfitri Bustamam, Runinda Pradnyamita, Citra Ayu Aprilia, Wahyukarno \\ Fakultas Kedokteran Universitas Pembangunan Nasional "Veteran" \\ Jakarta
}

\begin{abstract}
Background: In 2010, students of Faculty of Medicine, Universitas Pembangunan Nasional Veteran Jakarta who were graduated from the competency-based curriculum (CBC) in pre-clinical phase have entered the teaching hospital for their clinical rotation phases, while students who were graduated from the conventional curriculum still learned in the same teaching hospital.

Objective: This study aimed to evaluate the students competencies during the clinical rotation phase, between students who were graduated from CBC compare to students who were graduated from conventional curriculum.

Methods: This was a cross sectional study using 4-point Likert scale questionnaire. The population of this study were all students in clinical stage at Gatot Soebroto Hospital. The sample were 40 students from each group. Data was collected from December 2010 to January 2011. Chi-square test was used to analyze the data.

Results: This study showed that the students competencies in $C B C$ curriculum were higher in CBC significant correlation between pre-clinical curriculum with student's competencies in communication and behavior $(p=0.006)$, science session and scientific report $(p=0.000)$, and physical examination $(p=0.000)$. However, it is found that there were no correlation between pre-clinical curriculum with student's competencies in history taking, laboratory examination, making a diagnosis, and patient management ( $p>0.05$ ).

Conclusion: Student competencies higher in CBC curriculum compare to conventional curriculum, and particularly significant in physical examination, communication $\mathcal{E}$ behavior and scientific report $\mathcal{E}$ science session competencies.
\end{abstract}

Keywords: competency-based curriculum, student's competencies, clinical rotation phase

\begin{abstract}
Abstrak
Latar Belakang: Pada tahun 2010 mahasiswa Fakultas Kedokteran Universitas Pembangunan Nasional "Veteran" Jakarta (FKUPN) lulusan kurikulum berbasis kompetensi (KBK) pada tahap pendidikan Program Studi Sarjana Kedokteran (PSSK) telah memasuki Program Studi Profesi Dokter (PSPD) di rumah sakit pendidikan, sementara masih ada mahasiswa lulusan kurikulum konvensional di RS tersebut.

Tujuan: Penelitian ini bertujuan untuk mengevaluasi kompetensi mahasiswa KBK dibandingkan dengan mahasiswa kurikulum konvensional pada tahap profesi.

Metode: Penelitian ini menggunakan desain potong lintang dan kuesioner dengan 4 skala Likert. Populasi penelitian adalah mahasiswa tahap PSPD di RS Pendidikan Gatot Soebroto. Besar sampel kedua kelompok masing-masing sebesar 40 orang. Data diambil pada bulan Desember 2010-Januari 2011. Uji Chi-square digunakan untuk menganalisis data.

Hasil: Penelitian ini menunjukkan bahwa kompetensi mahasiswa dengan kurikulum KBK lebih baik. Ada hubungan antara kurikulum PSSK dengan kompetensi mahasiswa pada PSPD dalam komunikasi \& behaviour ( $\mathrm{p}=0,006)$, kompetensi yang berkaitan dengan laporan dan science session $(p=0,000)$, serta pemeriksaan fisik $(p=0,000)$.
\end{abstract}

Korespondensi:nurfitri_fkupn@yahoo.co.id; Telp. 081586148465/02192348161 
Namun, tidak ada hubungan antara kurikulum PSSK dengan kompetensi mahasiswa dalam anamnesis, pemeriksaan penunjang, diagnosis, dan penatalaksanaan $(\mathrm{p}>0,05)$.

Kesimpulan: Kompetensi mahasiswa KBK lebih baik dibanding mahasiswa kurikulum konvensional, terutama dalam kompetensi pemeriksaan fisik, komunikasi \& behavior dan laporan \& science session.

Kata Kunci: kurikulum berbasis kompetensi-kompetensi mahasiswa-program pendidikan profesi dokter

\section{PENDAHULUAN}

Sejak tahun 2006, Fakultas Kedokteran Universitas Pembangunan Nasional "Veteran" Jakarta (FK UPN) telah mengimplementasikan kurikulum berbasis kompetensi (KBK) dengan strategi student centered, problem based, integrated, community based, elective/ early clinical exposure and systematic (SPICES). Dalam kurikulum tersebut, pendidikan dokter dibagi menjadi dua tahap, yaitu tahap pendidikan Program Studi Sarjana Kedokteran (PSSK) dan Program Studi Profesi Dokter (PSPD). Pada tahun 2010, mahasiswa lulusan KBK pada tahap pendidikan PSSK telah memasuki tahap pendidikan PSPD di rumah sakit pendidikan FK UPN yaitu di RSPAD Gatot Soebroto, sementara masih ada mahasiswa lulusan kurikulum konvensional yang sedang menjalani pendidikan di Rumah Sakit tersebut.

Apakah perbedaan antara kurikulum konvensional dan KBK? Kurikulum konvensional adalah kurikulum nasional yang didasarkan pada keputusan Menteri Pendidikan dan Kebudayaan Nomor 056/U/1994. Pendekatan kurikulum didasarkan pada substansi keilmuan serta berbasis isi (content based curriculum), dan sasarannya adalah penguasaan bidang ilmu tersebut. Kurikulum konvensional bersifat teacher centered dengan metode belajar mengajar kuliah dan praktikum. Kurikulum tersebut menggunakan dua bentuk ujian, yaitu multiple choice questions (MCQ) yang lebih bersifat hapalan dan ujian praktikum.

Sebaliknya KBKadalah kurikulum yang menitikberatkan pada pencapaian kompetensi lulusannya. Di dalam Standar Kompentensi Dokter Indonesia disebutkan lulusan dokter harus memenuhi tujuh standar kompetensi, yaitu: 1) komunikasi efektif, 2) keterampilan klinis, 3) landasan ilmiah ilmu kedokteran, 4) pengelolaan masalah kesehatan, 5) pengelolaan informasi, 6) mawas diri dan pengembangan diri, 7) etika, moral, medikolegal dan profesionalisme serta keselamatan pasien. ${ }^{1} \mathrm{KBK}$ bersifat student centered yang menekankan pada fasilitasi pembelajaran pada mahasiswa. Mahasiswa dengan bimbingan dosen menentukan tujuan pembelajaran, memilih sumber pembelajaran yang sesuai dengan tujuan pembelajaran, menentukan urutan dan langkah pembelajaran, dan bertanggung jawab menilai kemajuan pembelajarannya sendiri. Pembelajaran student-centered bersifat aktif. ${ }^{2}$

Berdasarkan Standar Kompetensi Dokter Indonesia dan Standar Pendidikan Profesi Dokter serta visi misi fakultas, FK UPN menyusun KBK dengan beberapa program pembelajaran, yaitu Fundamental of Biomedical Science, Biomedical Programme, Clinical Skills Programme, Bioethics and Humanities Programme, Community Research Programme, dan Community Health Oriented Programme. Metode pembelajaran yang digunakan adalah tutorial problembased learning, skills lab, laboratory activity, expert lecture, dan extramural. Untuk mengetahui pencapaian belajar mahasiswa, ujian yang digunakan antara lain Objective Structured Clinical Examination (OSCE), Student Oral Case Analysis (SOCA), dan MCQ dengan clinical vignette.

Metode pembelajaran utama dalam KBK adalah PBL yang dianggap mampu menyiapkan mahasiswa untuk menjadi profesional dalam praktek, karena mendorong kemandirian, menstimulasi self-directed learning, memperkenalkan penalaran klinis (clinical reasoning), meningkatkan critical thinking, membuat putusan berdasarkan bukti, menjamin bahwa pengetahuan diperoleh dalam konteks yang terintegrasi, menawarkan latihan dan pengalaman dengan mengenalkan konsep profesional dan bahasa medis, serta mendukung kerja kelompok yang efektif dan komunikasi dengan sejawat. ${ }^{3}$ Yang juga tidak pernah diberikan dalam kurikulum konvensional adalah pembelajaran keterampilan klinis sejak awal pendidikan dokter secara berkesinambungan 
hingga akhir pendidikan dokter untuk mencapai standar kompetensi dokter. Pembelajaran keterampilan klinis pada awal pendidikan dokter dilaksanakan di laboratorium keterampilan klinis (skills lab). Dengan demikian mahasiswa KBK secara teoritis lebih siap daripada mahasiswa dengan kurikulum konvensional pada saat mengikuti pembelajaran di rumah sakit pendidikan, sebab mahasiswa dengan KBK telah dibekali keterampilan clinical reasoning, keterampilan klinis, kemampuan bekerja sama dalam tim, berkomunikasi, dan belajar mandiri.

Penelitian ini bertujuan untuk mengevaluasi kompetensi mahasiswa tingkat profesi yang mendapat pendidikan KBK dibandingkan dengan mahasiswa dengan kurikulum konvensional di RSPAD Gatot Soebroto.

\section{METODE}

Penelitian ini menggunakan desain potong lintang dengan populasi penelitian seluruh mahasiswa FK UPN tahap profesi di RSPAD Gatot Soebroto. Besar sampel untuk kedua kelompok mahasiswa (KBK dan konvensional) masing-masing sebesar 40 orang. Pengambilan data dilaksanakan pada bulan Desember 2010-Januari 2011.

Mahasiswa diminta untuk menilai apakah pendidikan tahap PSSK telah membantu mencapai kompetensi yang berkaitan dengan anamnesis, pemeriksaan fisik, pemeriksaan penunjang, diagnosis, penatalaksanaan, komunikasi dan behaviour, serta laporan dan science session pada tahap pendidikan profesi menggunakan skala Likert, yaitu: $1=$ kurang sekali, $2=$ kurang, $3=$ cukup, dan $4=$ baik. Kuesioner yang digunakan telah diuji validitas dan reliabilitasnya pada 30 orang mahasiswa sebelum diberikan kepada subjek penelitian yang sebenarnya. Nilai jawaban kuesioner ditentukan dengan menjumlahkan skor dari sejumlah pertanyaan untuk setiap kemampuan, selanjutnya total skor dikelompokkan menjadi dua, yaitu baik (skor e" $80 \%$ total skor) dan kurang (skor $<80 \%$ total skor).

Metode statistik yang digunakan untuk menganalisis data adalah uji Chi-square.

\section{HASIL}

Pada penelitian ini kompetensi anamnesis mencakup: melakukan anamnesis secara sistematis dan terarah, mengidentifikasi masalah dan membuat diagnosis banding, serta menjelaskan alasan klinis pernyataan dalam keluhan utama, riwayat penyakit sekarang, riwayat penyakit dahulu dan faktor risiko yang berhubungan dengan masalah pasien. Hasil uji Chi square menunjukkan tidak ada hubungan antara kurikulum PSSK dengan kompetensi anamnesis $(\mathrm{p}=0,180)($ Tabel 1$)$.

Tabel 1. Distribusi subjek penelitian berdasarkan kurikulum PSSK dan kompetensi dalam anamnesis tahap PSPD

\begin{tabular}{lrrrrrrr} 
& \multicolumn{8}{c}{ Kompetensi: Laporan dan Science Session } \\
\multirow{2}{*}{ Kurikulum PSSK } & \multicolumn{2}{c}{ Kurang } & \multicolumn{2}{c}{ Baik } & \multicolumn{2}{c}{ Total } & Nilai p \\
& \multicolumn{1}{c}{ n } & \multicolumn{1}{c}{$\mathbf{n}$} & $\%$ & $\mathbf{n}$ & $\%$ & \\
Konvensional & 18 & 45,0 & 22 & 55,0 & 40 & 100 & \\
KBK & 0 & 0,0 & 40 & 100,0 & 40 & 100 & 0,000 \\
Junnlah & 18 & 22,5 & 62 & 77,5 & 80 & 100 & \\
\hline
\end{tabular}

Pada penelitian ini kompetensi pemeriksaan fisik mencakup: melakukan pemeriksaan fisik sesuai prosedur dan menjelaskan alasan klinis (clinical reasoning) dalam pemeriksaan fisik dikaitkan dengan ilmu kedokteran dasar. Hasil uji Chi square menunjukkan ada hubungan antara kurikulum PSSK dengan kompetensi pemeriksaan fisik. $(p=0,000)($ Tabel 2). 
Tabel 2. Distribusi subjek penelitian berdasarkan kurikulum PSSK dan kompetensi pemeriksaan fisik tahap PSPD

\begin{tabular}{|c|c|c|c|c|c|c|c|}
\hline \multirow{3}{*}{ Kurikulum PSSK } & \multicolumn{6}{|c|}{ Kompetensi Pemeriksaan Fisik } & \multirow{3}{*}{ Nilai $p$} \\
\hline & \multicolumn{2}{|c|}{ Kurang } & \multicolumn{2}{|c|}{ Baik } & \multicolumn{2}{|c|}{ Total } & \\
\hline & $\mathbf{n}$ & $\%$ & n & $\%$ & $\mathbf{n}$ & $\%$ & \\
\hline Konvensional & 34 & 85,0 & 6 & 15,0 & 40 & 100 & \\
\hline KBK & 18 & 45,0 & 22 & 55,0 & 40 & 100 & 0,000 \\
\hline Jumlah & 52 & 65,0 & 28 & 35,0 & 80 & 100 & \\
\hline
\end{tabular}

\section{Pemeriksaan Penunjang}

Kompetensi pemeriksaan penunjang tidak berhubungan dengan kurikulum PSSK ( $\mathrm{p}=$ 0,086) (Tabel 3). Pada penelitian ini kompetensi dalam pemeriksaan penunjang mencakup: mengusulkan pemeriksaan penunjang (dikaitkan dengan alasan klinis) dan menginterpretasikan hasil pemeriksaan penunjang dikaitkan dengan ilmu kedokteran dasar.

Tabel 3. Distribusi subjek penelitian berdasarkan kurikulum PSSK dan kompetensi dalam pemeriksaan penunjang tahap PSPD

\begin{tabular}{lcccccccc} 
& \multicolumn{9}{c}{ Kompetensi dalam Pemeriksaan Penunjang } & \multirow{2}{*}{ Kurikulum PSSK } & \multicolumn{2}{c}{ Kurang } & \multicolumn{2}{c}{ Baik } & \multicolumn{2}{c}{ Total } & \multirow{2}{*}{ Nilai p } \\
\cline { 2 - 6 } & $\mathbf{n}$ & $\%$ & $\mathbf{n}$ & $\%$ & $\mathbf{n}$ & $\%$ & \\
nonvensional & 36 & 90,0 & 4 & 10,0 & 40 & 100 & \\
KBK & 29 & 72,5 & 11 & 7,5 & 40 & 100 & 0,086 \\
Jumlah & 65 & 81,3 & 15 & 18,8 & 80 & 100 & \\
\hline
\end{tabular}

Termasuk dalam kompetensi diagnosis adalah: (definisi sampai dengan prognosis). Hasil uji Chi square menegakkan diagnosis berdasarkan anamnesis, menunjukkan tidak ada hubungan antara kurikulum pemeriksaan fisik dan pemeriksaan penunjang, serta PSSK dengan kompetensi diagnosis $(p=0,402)($ Tabel menjelaskan secara menyeluruh diagnosis yang diperoleh 4).

Tabel 4. Distribusi subjek penelitian berdasarkan kurikulum PSSK dan kompetensi dalam diagnosis tahap PSPD

\begin{tabular}{lccccccc} 
& \multicolumn{6}{c}{ Kompetensi dalam Diagnosis } & \multirow{2}{*}{ Nilai p } \\
\cline { 2 - 6 } Kurikulum PSSK & \multicolumn{2}{c}{ Kurang } & \multicolumn{2}{c}{ Baik } & \multicolumn{2}{c}{ Total } & \\
\cline { 2 - 6 } & $\mathbf{n}$ & $\%$ & $\mathbf{n}$ & $\%$ & $\mathrm{n}$ & $\%$ & \\
Konvensional & 34 & 85,0 & 6 & 15,0 & 40 & 100 & \\
KBK & 30 & 75,0 & 10 & 25,0 & 40 & 100 & 0,402 \\
Jumlah & 64 & 80,0 & 16 & 20,0 & 80 & 100 & \\
\hline
\end{tabular}


Untuk kompetensi penatalaksanaan klinik, uji statistik menunjukkan hubungan yang bermakna $(\mathrm{P}=0,0695)$ (Tabel 5). Pada penelitian ini kompetensi dalam penatalaksanaan mencakup: menjelaskan penatalaksanaan (farmakologi dan non farmakologi) pada pasien sesuai dengan diagnosis yang didapat, serta melakukan tindakan medis dasar sesuai dengan kompetensi dan standar prosedur yang ada, misalnya venapuncture, kateterisasi, dan menjahit.

Tabel 5. Distribusi subjek penelitian berdasarkan kurikulum PSSK dan kompetensi dalam penatalaksanaan tahap PSPD

\begin{tabular}{|c|c|c|c|c|c|c|c|}
\hline \multirow{3}{*}{ Kurikulum PSSK } & \multicolumn{6}{|c|}{ Kompetensi dalam Penatalaksanaan } & \multirow{3}{*}{ Nilai $p$} \\
\hline & \multicolumn{2}{|c|}{ Kurang } & \multicolumn{2}{|c|}{ Baik } & \multicolumn{2}{|c|}{ Total } & \\
\hline & $\mathrm{n}$ & $\%$ & n & $\%$ & $\mathrm{n}$ & $\%$ & \\
\hline Konvensional & 37 & 92,5 & 3 & 7,5 & 40 & 100 & \\
\hline KBK & 30 & 75,0 & 10 & 25,0 & 40 & 100 & 0,069 \\
\hline Jumlah & 67 & 83,8 & 13 & 16,3 & 80 & 100 & \\
\hline
\end{tabular}

Kompetensi komunikasi dan behaviour mencakup: membangun empati terhadap pasien dan keluarga pasien, berkomunikasi secara efektif dan bersikap terhadap pasien, keluarga, dan paramedis, melaporkan dan mempresentasikan laporan kasus dan bed side teaching secara sistematis, serta bekerjasama dalam tim. Ada hubungan antara kurikulum PSSK dengan kompetensi komunikasi dan behaviour $(\mathrm{p}=0,006)($ Tabel 6).

Tabel 6. Distribusi subjek penelitian berdasarkan kurikulum PSSK dan kompetensi dalam komunikasi dan behaviour tahap PSPD

\begin{tabular}{lccccccc} 
& \multicolumn{9}{c}{ Kompetensi dalam Komunikasi dan Behaviour } & & \multirow{2}{*}{ Nilai p } \\
\cline { 2 - 7 } Kurikulum PSSK & \multicolumn{2}{c}{ Kurang } & \multicolumn{2}{c}{ Baik } & \multicolumn{2}{c}{ Total } & \\
\cline { 2 - 7 } & $\mathbf{n}$ & $\%$ & $\mathbf{n}$ & $\%$ & $\mathrm{n}$ & $\%$ & \\
Konvensional & 22 & 55,0 & 18 & 45,0 & 40 & 100 & \\
KBK & 9 & 22,5 & 31 & 77,5 & 40 & 100 & 0,006 \\
Junnlah & 31 & 38,8 & 49 & 61,3 & 80 & 100 & \\
\hline
\end{tabular}

Kompetensi yang berkaitan dengan laporan dan science session mencakup: menyusun materi secara sistematis dan mudah dimengerti, mencari rujukan/ referensi yang valid dan terbaru, melakukan presentasi, serta kemampuan diskusi selama mengikuti journal reading/ referat. Kompetensi dalam laporan dan science session berhubungan dengan kurikulum PSSK $(p=0,000)$ (Tabel 7).

Tabel 7. Distribusi subjek penelitian berdasarkan kurikulum PSSK dan kompetensi yang berkaitan dengan laporan dan science session tahap PSPD

\begin{tabular}{|c|c|c|c|c|c|c|c|}
\hline \multirow{3}{*}{ Kurikulum PSSK } & \multicolumn{6}{|c|}{ Kompetensi: Laporan dan Science Session } & \multirow{3}{*}{ Nilai p } \\
\hline & \multicolumn{2}{|c|}{ Kurang } & \multicolumn{2}{|c|}{ Baik } & \multicolumn{2}{|c|}{ Total } & \\
\hline & $\mathrm{n}$ & $\%$ & $\mathrm{n}$ & $\%$ & $\mathrm{n}$ & $\%$ & \\
\hline Konvensional & 18 & 45,0 & 22 & 55,0 & 40 & 100 & \\
\hline KBK & 0 & 0,0 & 40 & 100,0 & 40 & 100 & 0,000 \\
\hline Jumlah & 18 & 22,5 & 62 & 77,5 & 80 & 100 & \\
\hline
\end{tabular}




\section{PEMBAHASAN}

Secara umum, kompetensi mahasiswa dengan kurikulum KBK lebih banyak masuk dalam kategori mencapai kompetensi baik meskipun demikian hanya kompetensi pemeriksaan fisik, komunikasi \& behavior dan laporan serta science session yang berhubungan secara signifikan.

\section{Pemeriksaan Fisik}

Kompetensi pemeriksaan fisik pada mahasiswa KBK lebih baik daripada mahasiswa konvensional $(p=0,000)$. Hal itu mungkin disebabkan kurikulum FK UPN khususnya Clinical Skill Programme yang diselenggarakan selama tujuh semester telah mempersiapkan mahasiswa lebih baik dalam keterampilan klinis, meskipun demikian penelitian cohort yang dilakukan oleh penulis tidak menemukan adanya perbedaan signifikan dalam keterampilan klinis mahasiswa. ${ }^{10}$

\section{Komunikasi dan Behaviour}

Hasil penelitian ini menunjukkan ada pengaruh kurikulum KBK di PSSK terhadap kompetensi dalam komunikasi \& behaviour $(\mathrm{p}=0,006)$. Mahasiswa menganggap telah dibekali kompetensi komunikasi \& behaviour lebih baik dalam KBK dibandingkan dengan mahasiswa kurikulum konvensional. Hal itu menunjukkan implementasi PBL di FKUPN telah dapat mengembangkan keterampilan komunikasi efektif. Dalam PBL mahasiswa diharuskan untuk berkomunikasi secara efektif untuk menyampaikan informasi dan berinteraksi dalam tutorial. ${ }^{4}$ PBL menjadikan mahasiswa sebagai kolaborator yang baik, sebab mahasiswa menjadi tahu bagaimana harus berperan dengan baik dalam tim. Kompetensi mahasiswa sebagai kolaborator yang baik dapat dilihat dari kemampuannya dalam menetapkan aturan, mengatasi perbedaan, dan bernegosiasi hingga mencapai kesepakatan, serta bersikap terbuka terhadap ide dari anggota kelompok tutorial lainnya. Hmelo-Silver menegaskan bahwa mahasiswa PBL mampu bekerjasama dalam memberikan penjelasan secara kolaboratif. 5 Selain melalui PBL, keterampilan komunikasi, empati, dan bekerjasama juga dikembangkan dalam kurikulum KBK FKUPN melalui kurikulum clinical skill programme, bioethics and humanities programme, dan community health oriented programme selama tujuh semester.
Sebaliknya, penelitian di Belanda tidak menemukan adanya perbedaan kompetensi bekerjasama dalam tim. ${ }^{6}$ Systematic review menunjukkan bahwa lulusan PBL lebih unggul dalam keterampilan komunikasi serta lebih apresiatif terhadap aspek etik dan hukum dalam layanan kesehatan. ${ }^{7}$ Penelitian lain juga menemukan bahwa lulusan PBL menilai dirinya lebih baik dalam keterampilan interpersonal. ${ }^{8}$

\section{Laporan dan Science Session}

Hasil penelitian ini menunjukkan ada pengaruh kurikulum KBK di PSSK terhadap kompetensi yang berkaitan dengan laporan $\&$ science session $(\mathrm{p}=0,000)$. Mahasiswa menganggap telah dibekali kompetensi yang berkaitan dengan laporan $\&$ science session lebih baik dalam KBK dibandingkan dengan mahasiswa kurikulum konvensional. Hasil serupa ditemukan dalam survei yang membandingkan kompetensi lulusan PBL (McMaster University) dengan lulusan konvensional (University of Toronto). ${ }^{9}$ Hal ini juga didukung oleh hasil penelitian yang menemukan mahasiswa PBL lebih baik dalam mengumpulkan informasi dibandingkan dengan mahasiswa konvensional. ${ }^{8}$

\section{Anamnesis, Diagnosis, Pemeriksaan Penunjang, dan Penatalaksanaan}

Ranah penalaran klinis mencakup mengumpulkan dan menginterpretasi data, menegakkan diagnosis, mengevaluasi pilihan terapi, serta mempertimbangkan dimensi psikososial suatu penyakit. ${ }^{11}$ Penalaran klinis merupakan proses kognitif yang penting untuk mengevaluasi dan mengelola masalah pasien ${ }^{12}$ dan merupakan kompenen sentral kompetensi dokter, sehingga pencapaian keterampilan penalaran klinis sangat perlu ditekankan dalam pembelajaran. ${ }^{13}$

Penelitian ini tidak menunjukkan hubungan kurikulum PSSK terhadap kompetensi dalam anamnesis $(p=0,180)$, pemeriksaan penunjang $(\mathrm{p}=0,086)$, diagnosis $(\mathrm{p}=0,402)$, dan penatalaksanaan $(p=0,069)$. Hasil serupa juga ditemukan dalam penelitian cohort yang menggunakan instrumen Dutch Progress Test untuk menilai perkembangan pengetahuan mahasiswa. ${ }^{10}$

Menurut Barrows \& Tamblyn Problem based learning yang merupakan metode pembelajaran dalam KBK 
mempunyai tujuan utama mendorong penalaran klinis atau keterampilan problem solving pada mahasiswa. ${ }^{14}$ Mereka mengasumsikan melalui paparan terus-menerus dengan real problem serta strategi solusi yang dicontohkan oleh tutor, mahasiswa akan memperoleh keahlian dalam mengevaluasi masalah pasien, memutuskan apa yang salah dan membuat putusan yang tepat untuk penatalaksanaan atau mengelola masalah pasien. Salah satu alasan bahwa PBL lebih sukses dalam mengajarkan keterampilan problem solving adalah konsep "inquiry skill" yaitu keterampilan umum yang dapat diaplikasikan untuk mengumpulkan, menginterpretasi, dan mengintegrasikan data dari masalah klinis. ${ }^{14}$

Bagaimana peran PBL dalam membentuk problem solving skills? Berdasarkan penelitian dalam psikologi kognitif ada tiga peran PBL, yaitu: 1) perolehan pengetahuan faktual dalam konteks pengetahuan tersebut akan digunakan, 2) penguasaan prinsip umum atau konsep sehingga dapat ditransfer untuk memecahkan masalah baru yang serupa, dan 3) perolehan contoh sebelumnya dapat digunakan untuk memecahkan masalah berdasarkan kemiripan atau pattern recogniton. ${ }^{14}$

PBL juga membentuk alur pikir (flow chart) dalam mendiagnosis melalui langkah menyusun sejumlah differential diagnosis dari suatu skenario, bertanya dan menguji differential diagnosis, dan akhirnya menegakkan diagnosis. ${ }^{15}$ Tutor harus memfasilitasi pembentukan alur pikir pada mahasiswa. Agar terdapat kesamaan, harus diformulasikan alur pikir yang benar. Alur pikir yang benar kemudian harus disampaikan pada tutor meeting dengan menitikberatkan kepada aplikasi ilmu dasar pada masalah klinis. Dengan demikian pakar ilmu kedokteran dasar terkait dengan skenario yang akan disusun haruslah dilibatkan untuk memformulasikan alur pikir serta memberikan penjelasan mengenai hal-hal penting yang harus difasilitasi selama proses tutorial. Jika alur pikir mahasiswa sudah dibentuk dalam proses tutorial dan diujikan dalam SOCA diharapkan kemampuan alur pikir mahasiswa di RS Pendidikan dapat dicapai.

Berdasarkan teori tentang PBL, seharusnya mahasiswa yang belajar dengan PBL lebih baik daripada mahasiswa non-PBL dalam penalaran klinis. Mengapa kemampuan penalaran klinis mahasiswa KBK FK UPN tidak lebih baik daripada mahasiswa konvensional? Salah satu hipotesisnya adalah pada KBK FK UPN ditambahkan sejumlah kompetensi yang menurut KKI penting sebagai kompetensi dokter, misalnya keterampilan berkomunikasi, keterampilan bekerjasama dalam kelompok (team work), memahami etik dan menguasai teknologi informasi. Perubahan kurikulum tersebut menyebabkan penekanan terhadap pembelajaran ilmuilmu dasar, misalnya anatomi, fisiologi, dan patologi secara terstruktur menjadi kurang. Hal tersebut berakibat terhadap rendahnya kemampuan mendiagnosis pada mahasiswa. Padahal diagnosis merupakan langkah awal dari seorang dokter untuk dapat melakukan penatalaksanaan dan membuat prognosis dengan tepat. ${ }^{15}$ Kurangnya pengetahuan ilmu dasar khususnya anatomi, fisiologi, dan patologi pada mahasiswa FK UPN dapat dilihat dari rendahnya rata-rata nilai ujian ilmu kedokteran dasar tersebut.

Seharusnya kurangnya pengetahuan ilmu kedokteran dasar khususnya anatomi, fisiologi, dan patologi pada mahasiswa FK UPN dapat dihindari, jika dalam proses pembelajaran di tutorial dan skills lab ketiga ilmu dasar tersebut selalu diingatkan/ ditekankan untuk digunakan dalam penalaran klinis. Perlu ditinjau kembali apakah instruktur sudah berperan sebagaimana mestinya dalam proses pembelajaran keterampilan klinis. Dalam proses keterampilan klinis, instruktur harus menekankan alasan dari suatu prosedur yang dilakukan. Alasan tersebut haruslah selalu dikaitkan dengan ilmu dasar (anatomi, fisiologi dan patologi). Jika dimungkinkan, sebelum kegiatan keterampilan klinis dimulai, diawali dengan penjelasan singkat mengenai pengetahuan ilmu dasar (anatomi, fisiologi dan patologi). Dalam pembelajaran di laboratorium (praktikum), perlu dicontohkan aplikasi ilmu dasar yang sedang dipelajari pada masalah klinis. Melalui perbaikan dalam proses pembelajaran tersebut diharapkan penalaran klinis mahasiswa FK UPN akan meningkat, sehingga mereka menjadi lebih baik dalam melakukan anamnesis, diagnosis, pemeriksaan penunjang dan penatalaksanaan di rumah sakit pendidikan.

\section{KESIMPULAN}

1. Kompetensi klinik mahasiswa kurikulum KBK secara umum lebih baik dibanding mahasiswa Kurikulum Konvensional. 
2. Kompetensi pemeriksaan fisik, komunikasi dan behavior, dan laporan \& science session pada mahasiswa kurikulum KBK lebih baik secara signifikan dibanding kompetensi pada mahasiswa Kurikulum Konvensional.

3. Tidak ada hubungan antara kurikulum tahap sarjana dengan kompetensi mahasiswa dalam anamnesis, pemeriksaan penunjang, diagnosis, dan penatalaksanaan pada tahap pendidikan profesi.

\section{SARAN}

Agar kompetensi mahasiswa FK UPN dalam anamnesis, diagnosis, pemeriksaan penunjang dan penatalaksanaan pada pendidikan tahap PSPD menjadi lebih baik, perlu dilakukan hal berikut:

1. Mengupayakan perbaikan dalam proses tutorial dengan cara meminta mahasiswa mengaitkan pengetahuan ilmu dasarnya dalam penalaran untuk memahami masalah klinis serta memfasilitasi terbentuknya alur pikir mahasiswa berkaitan dengan masalah pasien.

2. Pada pembelajaran di skills lab, instruktur perlu memfasilitasi mahasiswa agar memahami alasan (reasoning) yang dikaitkan dengan ilmu dasar dari suatu prosedur keterampilan yang dilakukan.

3. Pada pembelajaran di laboratorium (praktikum), perlu dicontohkan aplikasi ilmu dasar yang dipelajari dalam konteks masalah klinis.

\section{DAFTAR PUSTAKA}

1. Konsil Kedokteran Indonesia. Standar kompetensi dokter Indonesia. Jakarta, 2006.

2. Harden RM, Sowden S, Dunn WR. Educational strategies in curriculum development: the SPICES model. Medical Education. 1984;18:284-97.

3. Sefton A. Problem-based learning. In: Dent JA, Harden RM, editors. A practical guide for medical teachers. $2^{\text {nd }}$ ed. Edinburgh: Elsevier Churchill Livingstone, 2005:143-150.

4. Kaufman A. Implementing problem-based medical education. New York: Springer Publishing Company, 1985.
5. Hmelo-Silver CE. Problem-based learning: what and how do students learn? Educational Psychology Review. 2004;16(3): 235-66.

6. Prince KJA, van Eijs PWLJ, Boshuizen HPA, vander Vleuten CPM, Scherpbier AJJA. General competencies of problem-based learning (PBL) and non-PBL graduates. Medical Education. 2005;39:394-401.

7. Koh GC-H, Khoo HE, Wong ML, Koh D. The effects of problem-based learning during medical school on physician competency: a systematic review. CMAJ. 2008; 178(1):34-41.

8. Schmidt AG, Vermeulen L, Van der Molen HT. Longterm effects of problem-based learning: a comparison of competencies acquired by graduates of a problem-based and a conventional medical school. Medical Education. 2006;40:562-7.

9. Shin JH, Haynes RB, Johston ME. Effect of problembased, self directed undergraduate education on lifelong learning. Can Med Assoc J. 1993;148(6):9691075.

10. Peeraer G, De Winter BY, Muijtjens AMM, Remmen R, Bossaert L, Scherbier AJJA. Evaluating the effectiveness of curriculum change. Is there a difference between graduating students outcomes from two different curriculum? Medical Teacher. 2009; 31:e64-e68.

11. University of Washington. The clinical reasoning 'guidelines' for ICM II. The College Faculty of the University of Washington School of Medicine, 2005.

12. Rahayu GR. Perubahan paradigma dalam penalaran klinis (clinical reasoning): apa yang bisa kita lakukan? Jurnal Pendidikan Kedokteran dan Profesi Kesehatan Indonesia. 2007; 2(2): 65-73.

13. Norman GR. Research in clinical reasoning: past history and current trends. Medical Education. 2005;39:418-27.

14. Norman GR, Schmidt HG. The psychological basis of problem-based learning: a review of the evidence. Academic Medicine. 1992; 67:557-65.

15. Franklyn-Miller AD, Falvey EC, McCrory PR. Patientbased not problem-based learning: an Oslerian approach to clinical skills, looking back to move foward. Journal of Postgraduate Medicine. 2009;55(3):198-203. 